\title{
Process improvement cost management in the quality management system of an industrial enterprise
}

\author{
Alexander Aleksakhin ${ }^{1 *}$, Evgeniya Eliseeva ${ }^{1}$, Ivan Zaytsev ${ }^{1}$, Yuliya Aleksakhina ${ }^{2}$, and \\ Luydmila Kostygova ${ }^{1}$ \\ ${ }^{1}$ College of Economics \& Industrial Management, NUST MISIS, Russia, 119049, Moscow \\ ${ }^{2}$ Branch Economy Department, Moscow Polytechnic University, Russia, 107023, Moscow
}

\begin{abstract}
Modern enterprise management focuses on the principles and requirements of ISO 9000 standards. At present, the quality management of an organization is viewed as a system of interrelated processes aimed, firstly, at satisfying and anticipating consumer demands and, secondly, at improving the efficiency of work based on leadership of managers and active use of continuous improvement methods. Analysis and accounting of production costs must be carried out based on concepts and methods of quality management using a systematic approach. Quality is determined by several its components, forming a so-called quality loop. Quality is embedded in products from the very beginning and is controlled at all stages. A quality product is obtained only if the necessary requirements are met at all stages. Quality begins with research needs. This is the most important stage in the life cycle of any product, since it is on it that the overall design of the product is decided, the image is formed, the most common characteristics are determined. The proposed approach allows identifying and comprehensively representing the cost accounting process. The use of resource management activities at the enterprise allows reducing the share of material costs in the total costs of production and increases the efficiency of the organization.
\end{abstract}

\section{Relevance}

Modern enterprise management focuses on the principles and requirements of ISO 9000 standards. At present, the quality management of an organization is viewed as a system of interrelated processes aimed, firstly, at satisfying and anticipating consumer demands and, secondly, at improving the efficiency of work based on leadership of managers and active use of continuous improvement methods. Quality management of an organization is a process of its continuous improvement at each level of management, in each functional area of an organization, based on the use of all available resources. At the core of any organization is a business process. The key to quality management is to correctly identify the needs of the input process in order to obtain an effective output result. At the same time, organizations are faced with issues of controlling the receipt of non-conforming materials

* Corresponding author: alexakhin@mail.ru 
in the production process, their irrational use in the production process and the production of non-conforming finished products. Analysis and accounting of production costs must be carried out based on concepts and methods of quality management using a systematic approach. Management cost accounting should contain input control, cost control in the production process and analysis of the main indicators of quality output [1]. This approach allows identifying and fully representing the requirements of the internal and external environment of the organization. Analysis and assessment of costs and quality at each stage of the life cycle are necessary for managers to effectively perform their professional duties in various areas of management, since all types of management are ultimately focused on improving performance [2].

\section{Description of the methodology}

At each enterprise, a variety of factors, both internal and external, influence product quality. The internal ones are those related to the ability of an enterprise to produce products of proper quality, i.e. depend on the activities of the enterprise. They are numerous, they are classified into the following groups: technical, organizational, economic, social and psychological. Technical factors most significantly affect the quality of products, therefore, the introduction of new technology, the use of new materials, higher quality raw materials the material basis to produce competitive products [3]. Organizational factors are associated with the improvement of the organization of production and labor, increasing production discipline and responsibility for product quality, ensuring a production culture and an appropriate level of staff skills [4]. Economic factors are caused by the costs of production and sales of products, pricing policies and the system of economic incentives for staff to produce high-quality products. Socio-economic factors significantly influence the creation of healthy working conditions, dedication and pride in the brand of your company, moral incentives for employees - all of these are important components to produce competitive products. External factors in the conditions of market relations contribute to the formation of product quality [5]. First, they include market requirements, i.e. buyers, competition, etc. All these factors are interrelated and affect product quality.

Quality is determined by several its components, forming a so-called quality loop [1]. A quality loop is a closed sequence of measures that determine the quality of goods or processes at the stages of their production and operation. Quality is created and maintained at all stages of the quality loop, starting with the study of needs and market opportunities, that is, marketing, and ends with the disposal of a product that has served its time (Fig. 1).

It is enough not to give the quality proper attention at any one of the stages, as the quality of all products suffers, the image of the manufacturer falls, and the credibility of the manufacturer falls. Phases «quality loop»:

1. Marketing. Quality begins with research needs. This is the most important stage in the life cycle of any product, since it is on it that the overall design of the product is decided, the image is formed, the most common characteristics are determined. Errors at this stage are most critical, since, if the needs are incorrectly defined, at the end of the production chain you can get a product that you simply will not buy.

2. Design and Development. A quality product cannot be made on the basis of a bad project, which does not take into account all the features of the product, does not calculate all possible failures and failures, does not analyze every component of the product and its impact on the functioning of the product as a whole, does not optimize the cost of manufacture and subsequent maintenance.

3. Procurement. The necessary consumables are being procured and the technical equipment for production is being prepared. 
4. Pre-production. A good project needs to be transferred from the drawings and designs to physical form. This can be done only by qualitatively organizing production, that is, by planning all the manufacturing processes and control methods.

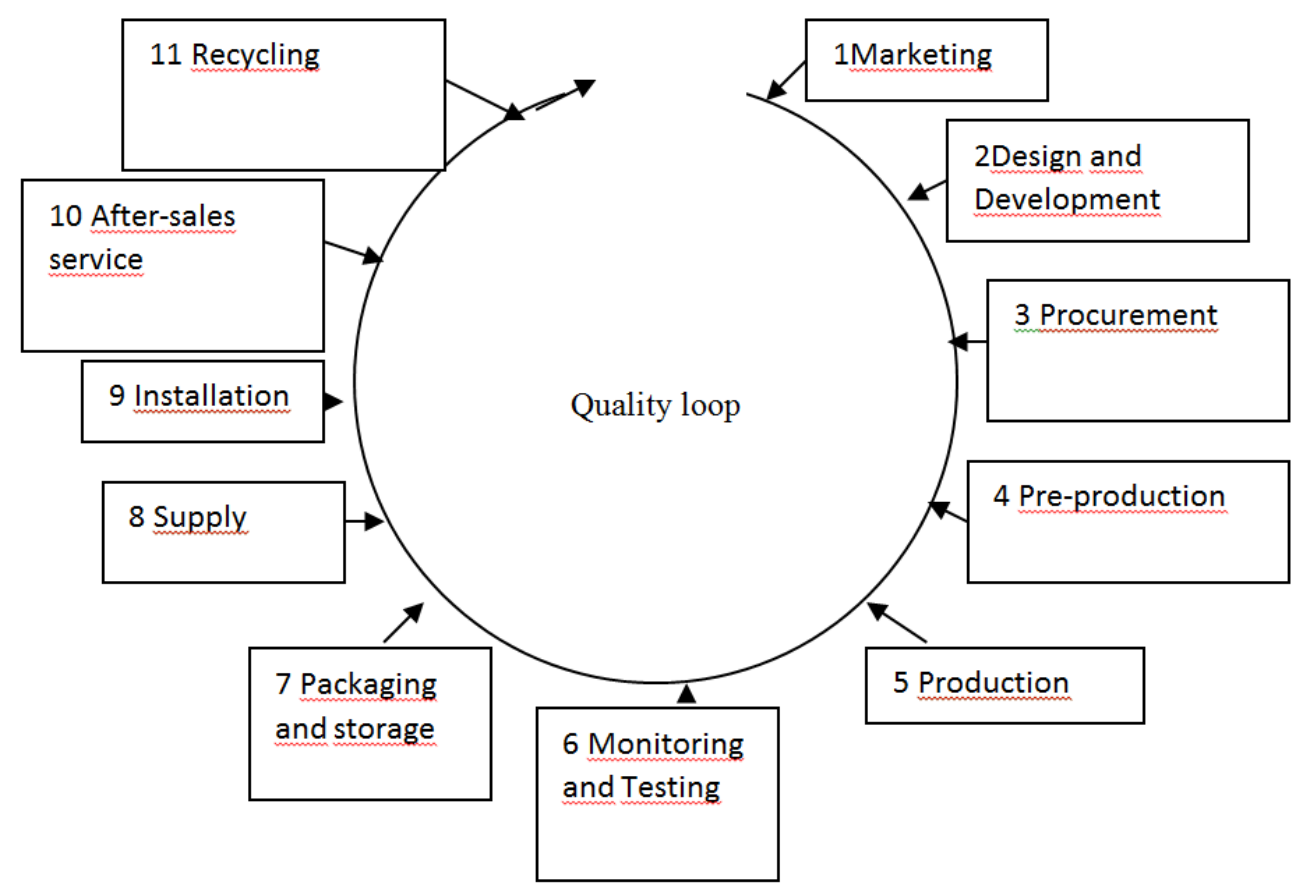

Fig. 1. Quality loop

\section{Production.}

6. Monitoring and Testing. Stage includes phased quality control.

7. Packaging and storage. Greatly made goods can be packaged in an uncomfortable or ugly packaging, and after a while consumer will begin to express their dissatisfaction, turn to more quality products of competitors.

8. Supply. Terms of sale are determined.

9. Intallation. Many products, in particular - complex household appliances, production equipment, computer equipment and communication facilities require professional installation and commissioning. If this is done incorrectly, some of the equipment capacity may not be used. Therefore, manufacturers try not to allow consumers to install complex products and do it themselves. A very common situation is when equipment mounted by non-professional experts can be removed from the guarantee and not serviced.

10. After-sales service.

11. Recycling. Disposal of goods after the end of life is also the task of the manufacturer. The manufacturer must design the product so that it can be safely and easily disposed of. The task of the manufacturer is to develop rules for utilization of products even during development. This requirement is particularly relevant in the light of the modern concept of sustainable development. One of its main provisions is that "... a production that is harmful to the environment cannot be commercially profitable." It should be noted that the manufacturer is not obliged to independently organize the disposal and recycling of products. It is important to provide technology and provide supervision for its observance. 
From all the above, we can draw the following conclusion: quality is embedded in products from the very beginning and is controlled at all stages. A quality product is obtained only if the necessary requirements are met at all stages. Quality begins with research needs. This is the most important stage in the life cycle of any product, since it is on it that the overall design of the product is decided, the image is formed, the most common characteristics are determined. Errors at this stage are most critical, since, if the needs are incorrectly defined, at the end of the production chain you can get a product that you simply will not buy. In quality management, there is a «tenfold cost rule» (Fig. 2). It says that the cost of producing low-quality products, the discovery of marriage increases ten times during the transition from the marketing stage, the design to the production stage, and from the production stage to the operational stage. In other words, if you correct some deficiency in the design costs 1000 rubles (say, to alter the drawing), but in production it will cost 10,000 rubles already (changeover of the production line), and after the sale already 100,000 rubles (recall of a consignment of goods from buyers) [1].

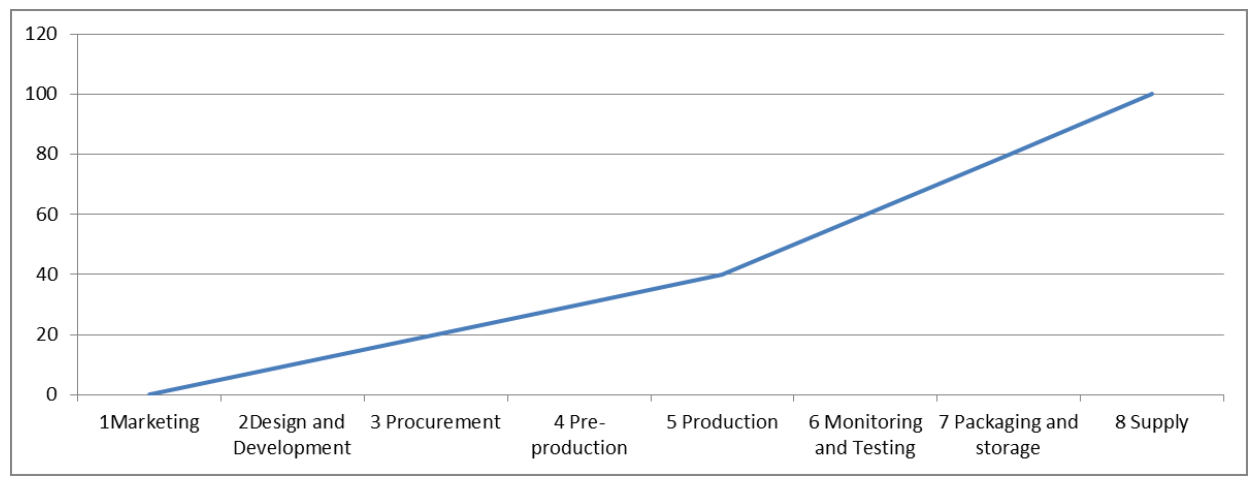

Fig. 2. Rule of tenfold cost

Great importance for the proper organization of cost accounting has their classification. Production costs are classified into current and capital costs. Current costs are the costs spent on the production and sale of products, works, services and affect the definition of profit. The impact of these costs is the place to be during the reporting period. Current costs include the costs of the enterprise for everyday needs. Capital costs represent all costs that occur in the processes of creation, acquisition, extension or improvement of assets intended for continued participation in the process of enterprise activity. Capital expenditure is the expenditure of capital on the modernization or purchase of labour, including premises and equipment, for a certain period. This is a large one-time cost $[11,13]$. In practice, the most common are the following groupings: by economic elements; costing items; places of occurrence; on processes; by the method of inclusion in the cost; depending on the volume of production.

Grouping by economic elements is necessary in order to determine exactly what resources are spent and what their specific weight in the total amount is [6]. Usually emit material costs; labor costs; deductions for social needs; depreciation; other expenses. This grouping does not show the appointment of production costs, their relationship with the results of production and feasibility. The grouping of costs by items of cost ensures the allocation of costs associated with the production of certain types of products. These costs are attributed directly or indirectly to products.

For the analysis of the effectiveness of the content of a subdivision, the grouping of costs by places of occurrence is used [7]. The places of origin at a manufacturing enterprise can be divisions of the main and auxiliary production, commercial and administrative 
services. When using a grouping of costs by process, all costs are localized depending on the direction of their use - in production, sales of products or in the management of an enterprise. This allows to assess the cost of the company's processes, which in turn makes it possible to more accurately determine the final cost of products (works, services).

In those industries where raw materials are processed into finished products consistently at separate production stages, a poperedelny method of accounting for production costs is used.

The remaining (auxiliary) production uses a simple cost accounting method for production. The average cost per unit of production is determined by the division of all production costs (for each item) by the number of finished products [6].

With the development of modern production, the share of direct costs in the cost of production is reduced, while up to overhead costs is rising. In this situation, the generally accepted approaches to the allocation of overhead costs can lead to incorrect management decisions. To avoid these errors allows the use of a functional method of calculating the cost of production (Activity Based Costing, ABC) [8].

The functional method became popular in the 1980s. It was developed by American scientists R. Cooper and R. Kaplan. Currently, it is actively used by $10 \%$ of large companies in the USA, Great Britain, Europe and Australia. This method is also of interest to Russian enterprises focused on creating strategic competitive advantages.

The functional method is based on the statement that the enterprise has a certain amount of resources, which allows it to perform production functions. These resources are distributed by function in proportion to the drivers of costs, that is, the cost-forming factors. The costs for each function are attributed to the object of calculation, which can be a product, service, customer, order [9].

The advantages of the functional method become apparent when a wide range of products is manufactured in one enterprise [10]. The fact is that in the production of dissimilar products, much more time and financial costs will be required for scheduling production, for setting up equipment, quality control, ordering and delivery of all components from the supplier and from the warehouse.

In this case, the cost drivers include: the number of equipment set-ups, the number of components and materials, the number of quality control checks and defect recovery operations. Knowing the cause of certain overhead costs, you can reasonably attribute them to the cost of a single product. Therefore, for each type of overhead it is necessary, first, to accurately determine the cost driver.

The approach to the distribution of overhead costs, provided for by the functional method, makes it possible to distribute overheads with greater accuracy and, therefore, more objectively calculate the costs of producing each type of product [1].

After determining the cost of production should assess the quality of the goods received. Product quality indicators are a quantitative characteristic of one or more product properties. The range of product quality indicators depends on the purpose of the product. In multi-purpose products, this nomenclature is more numerous. Product quality indicators are important in determining the level of product quality. The level of product quality is a relative characteristic of product quality, based on a comparison of the values of the product quality indicators of the product being evaluated with the basic values of the main indicators, that is, the values of the product quality indicators taken as the basis for a comparative assessment of its quality. The basic values can be taken as indicators of product quality, specified in the regulatory documentation (when monitoring product quality), as well as indicators of product quality of the best domestic and foreign samples (when determining the competitiveness of products). 
Under the competitiveness of products understand the degree of superiority of products from the point of view of consumers over other goods of similar purpose. Individual quality indicators for characterizing properties include [12]:

1) indicators of destination, determining the beneficial effect from the use of products;

2) the reliability indicator, which determines the ability to perform established functions, while maintaining its characteristics within the specified limits for the required period.

These are indicators of reliability, reliability (non-recoverable and recoverable), maintainability, persistence, durability.

3) indicators of manufacturability;

4) ergonomic and aesthetic;

5) standardization indicators;

6) economic indicators;

7) environmental performance.

Complex quality indicators characterize several product properties and consist of key defining indicators for which they decide to evaluate product quality.

The integral quality indicator is the ratio of the total beneficial effect from the operation or consumption of products to the total costs of its creation and operation (consumption).

The mixed method is based on the simultaneous use of single and complex indicators of product quality [13].

For the calculation and accounting of costs, as well as evaluation of product quality indicators, it is recommended to use the following methods:

1) settlement and measuring. Allows to determine costs using the established calculated norms of consumption and evaluate the quality indicators by comparing with accepted values optimal for the company;

2) registrational. Allows to determine costs based on observing and recording and counting the number of specific events, items or costs. Calculation method for determining product quality indicators uses customer requirements for products and manufacturer's manufacturing capabilities;

3) organoleptic. Allows to evaluate products on the analysis of the perception of the senses.

4) expert. Determination of costs and indicators using and estimating opportunity costs and indicators;

5) sociological. Allows to consider the requirements and opinions of actual or potential consumers of products.

6) statistical. Allows to determine costs, control them during the entire business process and analyze using the rules of mathematical statistics.

The process of cost management in the quality management system of an industrial enterprise implies the creation of economic conditions that encourage employees and teams of enterprises and departments to systematically improve and ensure the necessary level of quality. The development of market relations requires a wider use of economic methods of quality management. To such methods can be attributed: organizational-administrative, socio-psychological, organizational-technical, economic methods.

Organizational-administrative methods of the cost management process in the quality management system of an industrial enterprise are carried out through binding directives, orders, management instructions and other regulations aimed at improving and ensuring the required level of quality. These include regulation (functional, official, structural); standardization; rationing; instructing (explanations, explanations); administrative influence (based on orders, instructions, decrees, etc.).

Socio-psychological methods of cost management process in the quality management system of an industrial enterprise affect the socio-psychological processes occurring in work teams to achieve quality goals. In the field of quality management, they can be attributed to [15]: moral incentives for high-quality work results; methods of improving the 
collective psychological climate (the elimination of conflicts, the selection and provision of psychological compatibility of employees); consideration of the psychological characteristics of members of labor collectives; the formation of the motives of the work of staff aimed at achieving the required quality; preservation and development of the traditions of the enterprise to ensure the required quality; ways to increase self-discipline, responsibility.

Organizational and technical methods of cost management process in the quality management system of an industrial enterprise method include two groups [14]:

1) quality control methods: product, process;

2) quality control methods: process, product, process and product.

These methods allow you to control the quality of products and the quality of the process of its creation. The objects of application of quality control methods can be either a product or a process individually, or a product and process. At the same time, quality control includes checking the quality of work performance, their results and the actual achievement of quality goals. To do this, the organization solves the following tasks: planning, establishing norms, standards; creating standards for measuring the quality of work and their results; measurement of the quality parameters of works and products assessment of conformity and actual results of comparison of quality standards; conducting quality management activities, etc.

Economic methods of cost management in the quality management system of an industrial enterprise imply the creation of economic conditions that encourage employees and groups of enterprises and departments to systematically improve and ensure the necessary level of quality. The development of market relations requires a wider use of economic methods of quality management. Such methods may include: financing of activities in the field of quality management; economic accounting in the divisions of the quality management system; economic incentives for production; pricing of products and services based on their level of quality; the use of a wage system and material incentives; the use of economic measures to influence suppliers; business planning of creating new and modernized types of products and services.

\section{Results}

Determination, accounting and analysis of costs for the implementation of business processes and their economic assessment using quality indicators are practical tools for the development and implementation of cost reduction policies in the company based on the ISO 9001 standard and the tenfold cost rule. Cost accounting on the basis of adopted regulations is carried out on the basis of rules related to the preparation of external reporting of the enterprise. The main areas of the enterprise's work with suppliers in a modern environmental management system are the correlation of customer requirements and desires with the manufacturer's capabilities, considering the requirements of a modern industrial society. The definition of key indicators for assessing the capabilities and upgrading the technological equipment of an industrial enterprise is based on concepts and methods of quality management. Cost accounting on the basis of Russian regulations is carried out on the basis of rules related to the preparation of external reporting of the enterprise. The disadvantage of such accounting is its low efficiency, which does not allow for flexibility in the analysis of costs and the prevention of inconsistencies and deviations. Such a system of accounting does not allow an objective and complete understanding of where and how the process of forming the costs of the enterprise. As a result, it is impossible to control costs, as well as to look at effective and rational ways to reduce costs. In the practice of quality management in solving real problems, an analytical approach is used. This approach allows identifying and comprehensively representing the cost 
accounting process. The use of resource management activities at the enterprise allows reducing the share of material costs in the total costs of production and increases the efficiency of the organization.

\section{References}

1. E. Eliseeva, The management of quality, Textbook, Ed. House MISiS, (2013)

2. A. Anisimov, A. Obukhov, Y. Aleksakhina, A. Zhaglovskaya, A. Kudra, International Journal of Economic Perspectives 2, 442 (2017)

3. A. Yurievich, Y. Kostyukhin, O. Skryabin, I. Androsova, A. Zhaglovskaya, Int J Adv Biotechnol Res, 3, 2075-2082 (2017)

4. D. Savon, A. Zhaglovskaya, A. Safronov, D. Sala, Eurasian Mining 1, 9-11 (2018)

5. L. Kostygova, 16th international multidisciplinary scientific GEOconference SGEM 2016, Bulgaria, 381-388 (2016)

6. M. Eskindarov, Entrepreneurship development: concept, digital technology, efficient system, Publishing and trading Corporation "Dashkov and K" (2019)

7. N. Vikhrova, 18th International multidisciplinary scientific GEO conference SGEM, 18, 477-484 Albena, Bulgaria (2018)

8. S. Shchepetova, Management and Economics of quality: from natural to formal, from formal to natural, Komkniga (2006)

9. E. Eliseeva, N. Shmeleva, 16th Internrtional multidisciplinary scientific GEOconference SGEM 2016, Bulgaria, p. 3-10 (2016)

10. I. Muradov, E. Sidorova, 18th International multidisciplinary scientific GEO conference SGEM, 18, 407-414, Albena, Bulgaria (2018)

11. GOST R ISO 9004-2010 Quality management Systems. Recommendations for improvement, available at: http://protect.gost.ru (accessed: 20.02.2019)

12. T. Salimova, Quality Management: Textbook, Publishing House "Omega-L" (2013)

13. E. Eliseeva, 17th International multidisciplinary scientific GEOconference SGEM, Bulgaria, p. 249-254 (2017)

14. GOST R ISO 9001-2015 Quality management Systems. Requirements, available at: http://protect.gost.ru (accessed: 20.02.2019)

15. A. Aleksakhin, A. Anisimov, Y. Polozhentseva, A. Zhaglovskaya,, Eurasian mining, 2, p. 53-56 (2017) 